\title{
Life-event specificity: bipolar disorder compared with unipolar depression
}

Georgina M. Hosang, Ania Korszun, Lisa Jones, Ian Jones, Peter McGuffin and Anne E. Farmer

\section{Background}

Little is known about the impact of different types of stressful events (for example divorce $v$. bereavement) on unipolar depression compared with bipolar disorder. Inconsistencies exist concerning the association between independent events (beyond an individual's control, such as bereavement) and bipolar disorder.

\section{Aims}

To examine the role of specific, independent and dependent events in mood disorders.

\section{Method}

Life-event information was collected from 512 people with bipolar disorder, 1448 people with unipolar depression and over 600 controls.

\section{Results}

Various events were associated with unipolar depression and bipolar disorder, but some event specificity was detected. For example, financial crisis was more strongly related to bipolar disorder rather than unipolar depression. Independent events were only related to unipolar depression and not bipolar disorder.

\section{Conclusions}

The events that were linked to bipolar disorder and unipolar depression were similar. Independent events were not associated with bipolar episodes, suggesting that life stress may be a consequence of, rather than a trigger for, bipolar episodes.

\section{Declaration of interest}

G.M.H. and A.E.F. have provided sponsored talks for BristolMyers Squibb
Stressful life events have been associated with both unipolar depression and bipolar disorder. ${ }^{1-4}$ Stressful events that have been linked to both disorders include divorce/separation, personal illness, work-related and interpersonal problems. ${ }^{5-9}$ Examining the role of specific events (for example bereavement $v$. divorce) in unipolar depression and bipolar disorder may elucidate disorder-specific associations. There are several benefits to identifying whether certain events are strongly linked to unipolar depression and bipolar disorder. First, this would be clinically valuable, the occurrence of a life event known to be depressogenic will be a warning sign that an individual with a mood disorder may be at risk of relapse. Therefore clinicians, the individual and family members will know that additional monitoring, support and/or treatment is required to avoid the development of an illness episode. Second, identification of events associated with episodes of unipolar depression and bipolar disorder will provide an insight into possible mechanisms that explain the relationship between stress and mood disorders. Understanding such mechanisms will inform intervention and treatment strategies. For instance, research shows that humiliating events (rendering a person devalued to themselves or others, such as infidelity of a partner) trigger depressive episodes. ${ }^{10}$ In the face of such an event, psychological interventions can focus on processing the humiliating element of the event in an adaptive and positive way.

Comparing the relationship between specific events in unipolar depression and bipolar disorder has not been a focus of research. The available literature indicates that work-related difficulties and failures characterise bipolar disorder, whereas somatic illnesses are more salient for unipolar depression. ${ }^{8}$ Moreover, there is a difference in the types of stressful events associated with mania and depression in bipolar disorder; with personal illness being linked to bipolar depression, ${ }^{11}$ whereas bereavement characterises mania. ${ }^{12}$ The majority of studies addressing these issues are limited by their small samples, which makes generalising the results problematic. Replication and extension of this work in larger samples is required. Although establishing an association between life stress and mood disorders is important, it is helpful to determine the direction of this association. To do this researchers have distinguished between events that are independent (beyond an individual's control, such as bereavement) and dependent (related to a person's psychopathology and actions, such as being arrested). This distinction provides some insight as to whether the occurrence of a life event is a cause (independent event) or consequence (dependent event) of mood disorders, or other illnesses. ${ }^{13}$ Independent events have been consistently associated with the onset of unipolar depression ${ }^{4,14}$ and subsequent episodes. Research shows that having one severe independent event is sufficient to trigger an episode of unipolar depression. ${ }^{14}$ In terms of bipolar disorder, the evidence is more mixed, with some studies reporting a significant relationship between independent events, bipolar depression ${ }^{15,16}$ and mania; ${ }^{17}$ whereas others have failed to detect such a relationship. ${ }^{18-20}$ It is unclear whether experiencing a stressful event may trigger the illness or episode onset in bipolar disorder and this warrants further investigation. The objectives of this study were fourfold. First, the role of specific events in bipolar disorder and unipolar depression were examined. Second, the pertinence of different events on unipolar depression compared with bipolar disorder was explored. Third, the role of independent and dependent events in unipolar depression and bipolar disorder were investigated. Finally, the salience of independent and dependent life events on bipolar disorder compared with unipolar depression was examined.

\section{Method}

\section{Participants}

The sample were recruited for two case-control genetic association studies, one focused on unipolar depression ${ }^{21}$ and the other focused on bipolar disorder. ${ }^{22}$ There were a total of 512 people with bipolar disorder (bipolar group) and 1448 people 
with unipolar depression (unipolar group). A total of 1346 controls were recruited for both studies but were selected in the present investigation to match the mean age (plus or minus 1 standard deviation) of the bipolar group (26-49 years, $n=612$ ) and unipolar group (24-49 years, $n=679)$ at the time of their self-defined worst affective episodes. This was to prevent the confounding effect of age at interview, since we previously reported a negative association between age at index period and number of life events in this sample. ${ }^{1}$ The demographic and clinical characteristics of the participants are presented in Table 1.

The majority of participants in the unipolar group were recruited from out-patient psychiatric clinics in the UK, a smaller proportion were enlisted via self-help groups, general practice and media advertisement, during the years 2001-2004 from London, Birmingham and Cardiff. Individuals were only included if they had experienced two or more major depressive episodes of at least moderate severity that fulfilled operational criteria for recurrent unipolar depression according to the DSM-IV. ${ }^{23}$ The exclusion criteria were: intravenous drug dependence, depression occurring only in relation to substance misuse or medical illness, and/or having a personal or family history of mania or schizophrenia (the latter exclusion criterion was so that participants in the unipolar group had a low risk of switching diagnosis, research shows that having a family history of bipolar disorder or schizophrenia are significant risk factors for such diagnostic conversions ${ }^{24}$ ).

Participants in the bipolar group fulfilled DSM-IV criteria for bipolar I or II disorder, the majority of which were recruited from out-patient psychiatric clinics and the rest were enlisted via UKbased self-help groups and media advertisement between 2004 and 2007. Participants were excluded if their bipolar episodes only occurred in relation to substance misuse or a physical disorder or if they had a personal or family history of schizophrenia (research shows that approximately $20 \%$ of individuals initially diagnosed with bipolar disorder have a diagnostic switch to schizophrenia ${ }^{25}$ and a family history of schizophrenia is a risk factor for this diagnostic switch ${ }^{26}$ ).

Controls drawn from the unipolar depression study were selected from among 34371 participants originally recruited through general practices in the UK, to the Genetic and Environmental Nature of Emotional States in Siblings study and who fell into the bottom $20 \%$ of the distribution on the Sham Composite Index of liability to depression and anxiety ('G'). ${ }^{27}$ Those who responded positively to a postal invitation to participate were then contacted by telephone. Controls taken from the bipolar disorder study were recruited via newspaper advertisement and from staff working at King's College London but were not screened using the Sham Composite Index. The exclusion criteria for all controls from both the unipolar depression and bipolar disorder studies was a personal or family (first-degree relatives) history of any psychiatric disorder.

All participants were aged at least 18 years and provided written informed consent. The broad research aims of the studies were explained to the participants (increase knowledge of the causes and factors that make people vulnerable to bipolar disorder/unipolar depression), it was required that all participants agreed for their data to be analysed to address the team's research questions. All participants were informed that they could withdraw at any time, and that all of the information that they provided would be kept confidential and stored in an anonymised format. Ethical approval was obtained from the Joint South London and Maudsley, and Institute of Psychiatry Research Ethics Committee for both studies and from ethics committees in Birmingham and Cardiff for the unipolar depression study.

\section{Measures}

\section{Clinical assessment}

All participants in the unipolar and bipolar groups were interviewed face to face using the Schedule for Clinical Assessments in Neuropsychiatry, Version 2.1 (SCAN) $^{28}$ to establish a formal lifetime diagnosis of recurrent unipolar depression or bipolar disorder. The presence and severity of the psychopathology items were retrospectively rated by trained research assistants for the worst depressive episode in participants with unipolar depression and for participants with bipolar disorder for their worst depressive and manic episodes.

The 4- to 6-week peak intensity of symptoms within each worst episode was then used to rate the presence and severity of each SCAN item. The computerised version of the SCAN 2.1 is built on top of the iSHELL system (version 1.0.3.5 for Windows), which is a computer-aided personal interviewing tool produced by the World Health Organization and which provides DSM-IV operationally defined diagnoses.

\section{Screening questionnaire}

All controls received the Past History Schedule ${ }^{29}$ to assess lifetime psychopathology. This instrument has six items requiring a 'yes' or 'no' response. If the participants responded with a 'yes' for any item, further information was obtained to assess whether the participant was describing psychopathological symptoms.

\section{Present symptoms}

Participants completed the second edition of the Beck Depression Inventory (BDI-II) ${ }^{30}$ reporting on their mood over the previous 2

\begin{tabular}{|c|c|c|c|c|}
\hline & $\begin{array}{l}\text { Bipolar } \\
\text { group }\end{array}$ & $\begin{array}{l}\text { Unipolar } \\
\text { group }\end{array}$ & $\begin{array}{l}\text { Controls for comparison } \\
\text { with unipolar group }\end{array}$ & $\begin{array}{l}\text { Controls for comparison } \\
\text { with bipolar group }\end{array}$ \\
\hline$n$ & 512 & 1448 & 679 & 612 \\
\hline Women, $n(\%)$ & $339(66)$ & $1007(70)$ & $399(59)$ & $357(58)$ \\
\hline Age at interview, years: mean (s.d.) & 47.95 (11.39) & $47.32(12.36)$ & $37.36(7.93)$ & $38.72(7.14)$ \\
\hline \multicolumn{5}{|l|}{ Age at worst episode(s), years: mean (s.d.) } \\
\hline Depression & $37.42(11.78)$ & $36.56(12.27)$ & - & - \\
\hline Hypomania or mania & $37.28(11.35)$ & - & - & - \\
\hline Age at illness onset, years: mean (s.d.) & $21.80(18.55)$ & $23.25(11.59)$ & - & - \\
\hline \multicolumn{5}{|c|}{ Number of lifetime illness episodes, years: mean (s.d.) } \\
\hline Depression & $12.35(19.76)$ & $4.11(5.00)$ & - & - \\
\hline Hypomania or mania & $11.06(19.40)$ & - & - & - \\
\hline Diagnosis of bipolar I disorder, $n$ (\%) & $460(90)$ & - & - & - \\
\hline
\end{tabular}


weeks. This scale consists of 21 groups of 4 statements; each statement represents a different degree of severity. The participants endorsed one of the four statements in each group that reflected their mood over the past 2 weeks. Although, the BDI-II is a self-report measure, the items were read out to the participants by the researcher in the current investigation. This was to reduce the possibility for missing data and ensure the participant's comprehension of the statements. The total BDI-II score was used as a measure of severity of current depressive symptoms and no cut-offs were applied.

\section{Stressful life events}

The experience of 11 life events were recorded using the List of Threatening Experiences Questionnaire. ${ }^{31}$ This instrument is designed to detect events carrying significant long-term threat and particular salience for mood disorders. ${ }^{32}$ Previous analyses have shown that the List of Threatening Experiences Questionnaire successfully captures $82.5 \%$ of the life events covered in the more extensive life event interviews. ${ }^{31}$

Participants in the unipolar group reported the events that occurred 6 months before their worst depressive episode, and participants in the bipolar group recorded the events they experienced 6 months prior to their worst depressive and worst manic episodes. For controls the events occurring in the 6 months prior to interview were rated. The List of Threatening Experiences Questionnaire was administered by trained research assistants, this involved asking whether the participant experienced an event, confirming the event occurred during the index period and obtaining some contextual information to establish that the reference event fulfilled the classification of the items. Whereas the original instrument consists of 12 events, 2 of these were combined for the present study (these were: ' . . . did you have a separation due to marital difficulties' and ' . . . did you break off a steady relationship' combined to ' . . . did you have a separation due to marital difficulties or break off a steady relationship').

Drawing on previous research, ${ }^{31}$ events were divided into two broad categories: dependent (items 5-11, Table 2) and independent (items 1-4, Table 2). With one modification, that is the item 'valued item lost or stolen' has previously been classified as independent, however there is a high possibility that if the item were lost, negligence from the individual would have contributed to the occurrence of this event, therefore in this study it was categorised as a dependent event.

\section{Data analyses}

Logistic regression models were undertaken to test whether there were any differences in the proportions of participants in the unipolar and bipolar groups compared with controls reporting each event prior to their index periods. Caseness (bipolar disorder/unipolar depression or control) was used in these models as the dependent variable, and all 11 life events were entered into a logistic regression model simultaneously and used as predictor variables. Age at index period was included as a covariate. Given that our independent and dependent variables were categorical and we were keen to include covariates in our analyses, logistic regression models were the most appropriate statistical tests to use.

Logistic regression models were also used to compare the proportion of participants in the unipolar and bipolar groups reporting each event prior to their index periods and test for any differences. Caseness (bipolar disorder or unipolar depression) was used as the dependent variable. All 11 events were entered simultaneously into one logistic regression model and used as predictor variables. The BDI-II score was included as a covariate to account for the confounding effect of current mood; we previously reported a positive correlation between depressive symptoms and number of events recorded. ${ }^{3}$

\section{Results}

\section{Unipolar group $\boldsymbol{v}$. controls}

Six events were found to be more commonly reported by participants with unipolar depression prior to their worst depressive episode relative to controls prior to their interview (Table 2). Interestingly, significantly more controls reported the death of a relative or family friend compared with those in the unipolar group.

\section{Independent and dependent events}

A significantly greater proportion of participants in the unipolar group reported experiencing at least one dependent and independent life event 6 months before their worst depressive episode compared with controls for the 6 months prior to their assessment (Tables 3 and 4).

\section{Bipolar group $v$. controls}

A significantly larger proportion of participants in the bipolar group reported six events before their worst depressive episode

\begin{tabular}{|c|c|c|c|}
\hline \multirow[b]{2}{*}{ Event } & \multicolumn{2}{|c|}{ Participants reporting each event, $n(\%)$} & \multirow[b]{2}{*}{ OR $(95 \% \mathrm{Cl})^{\mathrm{a}}$} \\
\hline & Unipolar group $(n=1448)$ & Controls $(n=679)$ & \\
\hline 1. Serious illness, injury or an assault & $282(19.5)$ & $39(5.7)$ & $3.61(2.48-5.24)^{\star * *}$ \\
\hline 2. Serious illness, injury or assault of close relative & $280(19.3)$ & $110(16.2)$ & $0.97(0.73-1.29)$ \\
\hline 3. Death of spouse or first-degree relative & $175(12.1)$ & $23(3.4)$ & $4.11(2.54-6.64)^{\star * *}$ \\
\hline 4. Death of a close family friend or other relative & $183(12.6)$ & $103(15.2)$ & $0.60^{\mathrm{b}}(0.43-0.82)^{* * *}$ \\
\hline 5. Separation due to marital difficulties or break up of a steady relationship & $321(22.2)$ & $36(5.3)$ & $4.46(3.05-6.51)^{\star * \star}$ \\
\hline 6. Serious problem with a close friend, neighbour or relatives & $357(24.7)$ & $58(8.5)$ & $3.04(2.21-4.18)^{\star * *}$ \\
\hline 7. Job loss & $104(7.2)$ & $12(1.8)$ & $3.20(1.62-6.30)^{* * *}$ \\
\hline 8. Seeking work without success for more than 1 month & $103(7.1)$ & $25(3.7)$ & $0.98(0.57-1.66)$ \\
\hline 9. Major financial crisis & $199(13.7)$ & $27(4.0)$ & $2.38(1.50-3.80)^{* * *}$ \\
\hline 10. Problems with the police involving a court appearance & $58(4.0)$ & $10(1.5)$ & $1.63(0.77-3.45)$ \\
\hline 11. Valued item lost or stolen & $100(6.9)$ & $33(4.9)$ & $0.94(0.58-1.52)$ \\
\hline
\end{tabular}




\begin{tabular}{|c|c|c|c|}
\hline \multirow[b]{2}{*}{ Group and index period } & \multirow[b]{2}{*}{$n$} & \multicolumn{2}{|c|}{ Participants reporting at least one event 6 months leading up to their index periods, $n(\%)$} \\
\hline & & Dependent events & Independent events \\
\hline Controls for comparison with the unipolar group & 679 & $162(23.9)$ & $228(33.6)$ \\
\hline Controls for comparison with the bipolar group & 612 & $139(22.7)$ & $210(34.3)$ \\
\hline \multicolumn{4}{|l|}{ Unipolar group } \\
\hline Worst depressive episode & 1448 & $754(52.1)$ & $655(45.2)$ \\
\hline \multicolumn{4}{|l|}{ Bipolar group } \\
\hline Worst depressive episode & 512 & $249(48.6)$ & $188(36.7)$ \\
\hline Worst manic episode & 512 & $258(50.4)$ & $174(34.0)$ \\
\hline
\end{tabular}

\begin{tabular}{|c|c|c|c|c|c|c|c|c|}
\hline \multirow[b]{3}{*}{ Index period } & \multicolumn{4}{|c|}{ Dependent events } & \multicolumn{4}{|c|}{ Independent events } \\
\hline & \multicolumn{2}{|r|}{ Unadjusted } & \multicolumn{2}{|c|}{ Adjusted for age at index period } & \multicolumn{2}{|r|}{ Unadjusted } & \multicolumn{2}{|c|}{ Adjusted for age at index perioc } \\
\hline & $\beta$ & OR $(95 \% \mathrm{Cl})$ & $\beta$ & OR $(95 \% \mathrm{Cl})$ & $\beta$ & OR $(95 \% \mathrm{Cl})$ & $\beta$ & OR $(95 \% \mathrm{Cl})$ \\
\hline \multicolumn{9}{|l|}{ Unipolar group } \\
\hline Worst depressive episode & 1.24 & $3.47(2.83-4.25)^{* * *}$ & 1.29 & $3.68(2.93-4.48)^{* * *}$ & 0.49 & $1.63(1.35-1.98)^{* * *}$ & 0.54 & $1.71(1.40-2.09)^{* * *}$ \\
\hline \multicolumn{9}{|l|}{ Bipolar group } \\
\hline Worst depressive episode & 1.17 & $3.22(2.49-4.16)^{\star \star *}$ & 1.15 & $3.17(2.43-4.12)^{\star * *}$ & 0.11 & $1.11(0.87-1.42)$ & 0.10 & $1.11(0.86-1.43)$ \\
\hline Worst manic episode & 1.24 & $3.46(2.68-4.47)^{\star \star \star}$ & 1.26 & $3.51(2.69-4.57)^{\star * *}$ & -0.02 & $0.99(0.77-1.26)$ & -0.04 & $0.96(0.74-1.24)$ \\
\hline
\end{tabular}

relative to controls for the period prior to their interview (Table 5). Similar results were found for the worst manic episode (Table 6). Conversely, a significantly greater percentage of controls reported serious illness of a first-degree relative and death of family friend or other relative compared with those in the bipolar group for their worst depressive and manic episodes.

\section{Dependent and independent events}

Dependent events were found to be significantly more common before the worst manic and depressive episodes for participants in the bipolar group compared with controls for the period prior to their assessment (Tables 3 and 4). The proportion of those in the bipolar group and the controls reporting an independent event prior to their index periods was not significantly different.

\section{Bipolar disorder: worst manic episode v. worst depressive episode}

When comparing the percentage of participants with bipolar disorder reporting each of the 11 events prior to the worst depressive and worst manic episodes, only one significant difference was observed. That is, experiencing a serious problem with a friend, neighbour or relative was reported by significantly more participants in this group prior to their worst manic episode relative to their worst depressive episode (odds ratio $(\mathrm{OR})=1.36$, $95 \%$ CI $1.01-1.84, P \leqslant 0.05)$. No significant differences were found between the proportion in this group reporting an independent (OR $=0.89,95 \%$ CI $0.69-1.15, P=$ not significant $)$ or dependent $(\mathrm{OR}=1.07,95 \% \mathrm{CI} 0.84-1.37, P=$ not significant $)$ event before their worst depressive episode compared with their worst manic episode.

\section{Unipolar $\boldsymbol{v}$. bipolar group}

Eight events were recorded by a similar proportion of participants in the unipolar and bipolar groups for the 6 months prior to their worst affective episodes (Tables 7 and 8). However, the death of a spouse or first-degree relative was reported by significantly more participants with unipolar depression compared with bipolar disorder. The illness of a first-degree relative was reported by significantly more participants in the unipolar group prior to their worst depressive episode compared with those in the bipolar group for their worst depressive but not manic episodes.

Experiencing a financial crisis on the other hand was experienced by a significantly larger proportion of individuals in the bipolar group compared with the unipolar group prior to their worst affective episodes.

\section{Dependent and independent events}

A significantly greater percentage of participants in the unipolar group reported experiencing an independent event prior to their worst depressive episode relative to the bipolar group prior to the worst affective episodes (bipolar disorder worst depressive episode: $\mathrm{OR}=1.41,95 \%$ CI $1.11-1.77, P \leqslant 0.01$; worst manic episode: $\mathrm{OR}=1.59,95 \%$ CI $1.26-2.02, \quad P \leqslant 0.001)$. Events classified as dependent were reported by a similar proportion in both groups prior to their worst affective episodes (bipolar disorder worst depressive episode: $\mathrm{OR}=1.11,95 \%$ CI $0.89-1.40$; worst manic episode: $\mathrm{OR}=1.02,95 \%$ CI $0.82-1.28, P$ was not significant for either).

It should be noted that all analyses concerning the bipolar group were repeated with the exclusion of those diagnosed with bipolar II disorder and the results remained the same.

\section{Discussion}

\section{Specific events and unipolar depression}

Six events were associated with unipolar depressive episodes, including personal illness, job loss and financial crisis, consistent with the literature. ${ }^{9}$ The death of a friend or family member, other than a spouse or first-degree relative was reported by a higher proportion of controls compared with those in the unipolar or 
Table 5 Differences between bipolar group and controls for the events reported 6 months before their worst depressive episode and interview, respectively

\begin{tabular}{|c|c|c|c|}
\hline \multirow[b]{2}{*}{ Event } & \multicolumn{2}{|c|}{ Participants reporting each event, $n(\%)$} & \multirow[b]{2}{*}{ OR $(95 \% \mathrm{Cl})^{\mathrm{a}}$} \\
\hline & Bipolar group $(n=512)$ & Controls $(n=612)$ & \\
\hline 1. Serious illness, injury or an assault & $100(19.5)$ & $33(5.4)$ & $3.61(2.27-5.73)^{* * *}$ \\
\hline 2. Serious illness, injury or assault of close relative & $63(12.3)$ & $106(17.3)$ & $0.51^{\mathrm{b}}(0.34-0.77)^{* * *}$ \\
\hline 3. Death of spouse or first-degree relative & $30(5.9)$ & $22(3.6)$ & $1.98(1.03-3.78)^{\star}$ \\
\hline 4. Death of a close family friend or other relative & $60(11.7)$ & $93(15.2)$ & $0.54^{\mathrm{b}}(0.36-0.83)^{\star \star}$ \\
\hline 5. Separation due to marital difficulties or break up of a steady relationship & $112(21.9)$ & $28(4.6)$ & $4.40(2.75-7.04)^{* * *}$ \\
\hline 6. Serious problem with a close friend, neighbour or relatives & $114(22.3)$ & $52(8.5)$ & $2.30(1.54-3.44)^{* * *}$ \\
\hline 7. Job loss & $42(8.2)$ & $10(1.6)$ & $3.69(1.64-8.29)^{\star *}$ \\
\hline 8. Seeking work without success for more than 1 month & $36(7.0)$ & $20(3.3)$ & $0.93(0.46-1.88)$ \\
\hline 9. Major financial crisis & $87(17.0)$ & $25(4.1)$ & $2.85(1.67-4.87)^{\star \star \star}$ \\
\hline 10. Problems with the police involving a court appearance & $24(4.7)$ & $10(1.6)$ & $1.32(0.53-3.27)$ \\
\hline 11. Valued item lost or stolen & $37(7.2)$ & $28(4.6)$ & $0.78(0.40-1.49)$ \\
\hline
\end{tabular}

\begin{tabular}{|c|c|c|c|}
\hline \multirow[b]{2}{*}{ Event } & \multicolumn{2}{|c|}{ Participants reporting each event, $n$ (\%) } & \multirow[b]{2}{*}{ OR $(95 \% \mathrm{Cl})^{\mathrm{a}}$} \\
\hline & Bipolar group $(n=512)$ & Controls $(n=612)$ & \\
\hline 1. Serious illness, injury or an assault & $77(15.0)$ & $33(5.4)$ & $2.37(1.47-3.83)^{* * *}$ \\
\hline 2. Serious illness, injury or assault of close relative & $66(12.9)$ & $106(17.3)$ & $0.60^{\mathrm{b}}(0.40-0.88)^{* *}$ \\
\hline 3. Death of spouse or first-degree relative & $30(5.9)$ & $22(3.6)$ & $1.19(0.61-2.36)$ \\
\hline 4. Death of a close family friend or other relative & $54(10.5)$ & $93(15.2)$ & $0.47^{\mathrm{b}}(0.31-0.73)^{\star * *}$ \\
\hline 5. Separation due to marital difficulties or break up of a steady relationship & $102(19.9)$ & $28(4.6)$ & $4.05(2.51-6.54)^{\star * *}$ \\
\hline 6. Serious problem with a close friend, neighbour or relatives & $135(26.4)$ & $52(8.5)$ & $3.47(2.37-5.09)^{* * *}$ \\
\hline 7. Job loss & $35(6.8)$ & $10(1.6)$ & $3.24(1.41-7.43)^{\star *}$ \\
\hline 8. Seeking work without success for more than 1 month & $36(7.0)$ & $20(3.3)$ & $0.97(0.49-1.93)$ \\
\hline 9. Major financial crisis & $80(15.6)$ & $25(4.1)$ & $2.91(1.69-5.01)^{* * *}$ \\
\hline 10. Problems with the police involving a court appearance & $19(3.7)$ & $10(1.6)$ & $1.38(0.55-3.47)$ \\
\hline 11. Valued item lost or stolen & $31(6.1)$ & $28(4.6)$ & $0.77(0.39-1.50)$ \\
\hline
\end{tabular}

bipolar groups. Those in the unipolar group did report significantly more deaths of spouses or first-degree relatives, which substantiate findings from the literature. ${ }^{33}$ The impairments of mood disorders are far reaching and have an impact on employment and relationships. ${ }^{34,35}$ Such factors could limit the social network of people with mood disorders meaning they are less likely than unaffected individuals to experience certain events, such as illness or death of a family friend or relative, explaining the findings observed in this investigation.

The results of this study showed that dependent and independent events were associated with unipolar depressive episodes comparable with previous research. ${ }^{4,14}$ These findings suggest that the occurrence of stressful events may trigger an episode of unipolar depression. But also those individuals susceptible to depression may also generate their life stress (dependent events), as outlined in the stress generation theory. ${ }^{36}$ Symptoms such as irritability (characteristic of unipolar depression) may contribute to the occurrence of some events (such as interpersonal conflicts) possibly exacerbating depressive symptoms, potentially spiralling into a depressive episode. According to the stress generation theory, the relationship between life stress and unipolar depression is transactional, such that individuals with unipolar depression may contribute to the occurrence of stressful events, as well as reacting to them. ${ }^{36}$

\section{Specific events and bipolar disorder}

Findings from the present investigation also showed that six events were recorded by significantly more participants with bipolar disorder before their worst depressive episode compared with controls for the period before their assessment; a similar pattern was observed for the worst manic episode. The events included interpersonal problems, financial difficulties and job loss, which are consistent with existing research. ${ }^{7,12}$

Dependent events were associated with depressive and manic episodes in the bipolar group, consistent with studies applying the stress generation theory to bipolar disorder. ${ }^{37}$ Independent events were unrelated to bipolar episodes, supporting the results of previous studies, ${ }^{18}$ suggesting that the link between life stress and bipolar disorder maybe a consequence of the illness. Using a self-report checklist is not the most sensitive way of measuring independence and some events classified as dependent here should be reclassified as independent due to the context and biography of the person. It is important to employ more 


\begin{tabular}{|c|c|c|c|}
\hline \multirow[b]{2}{*}{ Event } & \multicolumn{2}{|c|}{ Participants reporting each event, $n$ (\%) } & \multirow[b]{2}{*}{ OR $(95 \% \mathrm{Cl})^{\mathrm{a}}$} \\
\hline & Bipolar group $(n=512)$ & Unipolar group $(n=1448)$ & \\
\hline 1. Serious illness, injury or an assault & $100(19.5)$ & $282(19.5)$ & $0.90(0.67-1.21)$ \\
\hline 2. Serious illness, injury or assault of close relative & $63(12.3)$ & $280(19.3)$ & $1.61(1.15-2.27)^{\star *}$ \\
\hline 3. Death of spouse or first-degree relative & $30(5.9)$ & $175(12.1)$ & $1.86(1.18-2.93)^{\star *}$ \\
\hline 4. Death of a close family friend or other relative & $60(11.7)$ & $183(12.6)$ & $0.94(0.66-1.35)$ \\
\hline 5. Separation due to marital difficulties or break up of a steady relationship & $112(21.9)$ & $321(22.2)$ & $1.07(0.81-1.41)$ \\
\hline 6. Serious problem with a close friend, neighbour or relatives & $114(22.3)$ & $357(24.7)$ & $1.11(0.84-1.46)$ \\
\hline 7. Job loss & $42(8.2)$ & $104(7.2)$ & $0.83(0.53-1.31)$ \\
\hline 8. Seeking work without success for more than 1 month & $36(7.0)$ & $103(7.1)$ & $1.12(0.70-1.80)$ \\
\hline 9. Major financial crisis & $87(17.0)$ & $199(13.7)$ & $1.48^{b}(1.04-2.10)^{*}$ \\
\hline 10. Problems with the police involving a court appearance & $24(4.7)$ & $58(4.0)$ & $0.96(0.54-1.71)$ \\
\hline 11. Valued item lost or stolen & $37(7.2)$ & $100(6.9)$ & $1.08(0.68-1.73)$ \\
\hline
\end{tabular}

\begin{tabular}{|c|c|c|c|}
\hline \multirow[b]{2}{*}{ Event } & \multicolumn{2}{|c|}{ Participants reporting each event, $n$ (\%) } & \multirow[b]{2}{*}{ OR $(95 \% \mathrm{Cl})^{\mathrm{a}}$} \\
\hline & Bipolar group $(n=512)$ & Unipolar group $(n=1448)$ & \\
\hline 1. Serious illness, injury or an assault & $77(15.0)$ & $282(19.5)$ & $1.27(0.93-1.73)$ \\
\hline 2. Serious illness, injury or assault of close relative & $66(12.9)$ & $280(19.3)$ & $1.36(0.97-1.90)$ \\
\hline 3. Death of spouse or first-degree relative & $30(5.9)$ & $175(12.1)$ & $2.25(1.39-3.64)^{* * *}$ \\
\hline 4. Death of a close family friend or other relative & $54(10.5)$ & $183(12.6)$ & $1.15(0.79-1.67)$ \\
\hline 5. Separation due to marital difficulties or break up of a steady relationship & $102(19.9)$ & $321(22.2)$ & $1.24(0.93-1.65)$ \\
\hline 6. Serious problem with a close friend, neighbour or relatives & $135(26.4)$ & $357(24.7)$ & $0.80(0.62-1.05)$ \\
\hline 7. Job loss & $35(6.8)$ & $104(7.2)$ & $1.16(0.71-1.88)$ \\
\hline 8. Seeking work without success for more than 1 month & $36(7.0)$ & $103(7.1)$ & $1.18(0.73-1.92)$ \\
\hline 9. Major financial crisis & $80(15.6)$ & $199(13.7)$ & $1.57^{\mathrm{b}}(1.10-2.23)^{*}$ \\
\hline 10. Problems with the police involving a court appearance & $19(3.7)$ & $58(4.0)$ & $0.99(0.54-1.80)$ \\
\hline 11. Valued item lost or stolen & $31(6.1)$ & $100(6.9)$ & $1.17(0.72-1.90)$ \\
\hline \multicolumn{4}{|c|}{$\begin{array}{l}\text { a. Reported OR for the prevalence of each life event among the unipolar group compared with the bipolar group. Adjusted for age at index period and depression symptoms. } \\
\text { b. This prevalence is higher among the bipolar group relative to the unipolar group. } \\
{ }^{*} P \leqslant 0.05, * \star P \leqslant 0.01 \text {. }\end{array}$} \\
\hline
\end{tabular}

sensitive life stress measures (for example the Life Events and Difficulties Schedule ${ }^{38}$ ) where independence can be established more readily.

\section{Bipolar disorder: depression v. mania}

Experiencing interpersonal problems was found to be more pertinent to mania than bipolar depression, a finding also reported by other studies. ${ }^{7,11}$ This contradicts a previous study that found that illness within the family and work-related difficulties were more strongly associated with mania than bipolar depression. ${ }^{7}$ However, this study consisted of 79 participants compared with 512 with bipolar disorder in the present investigation, suggesting that our failure to replicate Dunner et al's ${ }^{7}$ results is unlikely to be as a result of lack of power.

Moreover, similar proportions of those in the bipolar group reported dependent and independent events prior to their worst depressive and manic episodes, supporting prior research. ${ }^{39,40}$ But other studies have found that independent events are more common prior to a manic rather than a bipolar depressive episode. ${ }^{11,41}$ McPherson et $a l^{41}$ and Hall et al ${ }^{11}$ enquired about life events that occurred 3 months prior to relapse, whereas the present study focused on events experienced 6 months prior to the worst affective episodes. This 3-month difference increases the likelihood that an event may occur that may explain the discrepant findings.

\section{Unipolar depression $\boldsymbol{v}$. bipolar disorder}

Our findings suggest that the majority of life events associated with unipolar depression are equally important for bipolar disorder. However, death of a spouse or relative was found to be more pertinent to unipolar than bipolar episodes. Illness of a close relative was more salient to an unipolar rather than a bipolar depressive episode. We also found experiencing a financial crisis was more characteristic of bipolar rather than unipolar depressive episodes.

Other studies have reported different patterns of event specificity for unipolar depression and bipolar disorder. Bidzinska $^{8}$ recruited 50 participants with bipolar disorder and 47 with unipolar depression and found that work-related difficulties and failures characterised bipolar disorder, whereas somatic illnesses indexed unipolar depression. Differences in sample size and time frames are possible explanations of the differences found in this earlier study. ${ }^{8}$

In our study, $22 \%(n=114)$ of the bipolar group had a temporal overlap between their worst depressive and manic episodes; excluding these participants from all sets of analyses 
made little difference to the results. There was one exception: the association between financial crises and bipolar rather than unipolar depressive episodes was no longer significant.

\section{Methodological limitations}

The present study possesses a number of strengths (such as a large sample), but three methodological limitations must be considered when interpreting the results. First, all the participants in the unipolar and the bipolar groups recalled the events they experienced 6 months leading up to their worst affective episodes, which occurred on average 10 years prior to their participation. This may have resulted in retrospective reporting biases (for example normal forgetting). ${ }^{3}$ In the present study there were no significant differences in the recall periods between the unipolar and bipolar groups thus possible retrospective reporting biases are likely to apply equally to both groups. This suggests that retrospective biases have limited influence on the comparisons between unipolar and bipolar groups and any differences between the groups are likely to be the result of differential diagnoses.

Second, the controls used in the present study may be described as super healthy or resilient given that they have no personal or family history of any psychiatric disorder. By comparing such individuals to both our affected case groups, the differences are likely to be inflated. However, this issue does not invalidate our findings given that they are supported by previous studies using controls that were not screened for a personal or family history of any psychiatric disorder. ${ }^{42}$

Finally, using a life-event questionnaire has some limitations, including the participants' subjective interpretation as to what counts as an instance of a certain item and the misdating of events. Although we acknowledge that interviews are comprehensive and likely to be the optimum way of measuring life events, we also recognise that they are time and labour intensive resulting in high data collection costs, especially when applied to large samples similar to our own. Questionnaires in contrast are quick and easy to complete making them more affordable and suitable for large studies. Some information is lost when utilising questionnaires that create various problems (for example establishing independence). In the current study we attempted to compromise by using a researcher-administered questionnaire that attempts to surmount dating and contextual issues related to using a self-report questionnaire with the added benefit of reducing the time and expense of more lengthy interviews.

\section{Implications}

Similar types of stressful events were associated with unipolar depression and bipolar disorder highlighting their overlap. However, some event specificity was detected suggesting some distinction between these illnesses. There are various benefits to understanding the relationship between specific events and mood episodes. Clinically, experiencing a particular event will provide warning signs of possible relapse and thus a time for the individual's support network to offer additional monitoring and care. Our findings also have implications for gene-environment interaction research. Many of the studies exploring interactions between stressful events and genetic variants in mood disorders have focused on the number of life events ${ }^{43}$ or the reporting of at least one. ${ }^{44}$ But it is possible that certain events, such as those identified in this investigation, are driving this relationship. Future studies should therefore focus on exploring interactions between particular events and genetic factors in mood disorders.
Georgina M. Hosang, PhD, MRC Social, Genetic and Developmental Psychiatry Centre, Institute of Psychiatry, King's College London; Ania Korszun, PhD, MD, FRCPsych, Barts and The London School of Medicine and Dentistry, Queen Mary University of London; Lisa Jones, PhD, Department of Psychiatry, Neuropharmacology \& Neurobiology Section, University of Birmingham, National Neurophar Centre for Mental Health, Birmingham; Ian Jones, PhD, MRCPsych, Department of Psychological Medicine, Cardiff University, Cardiff; Peter McGuffin, MB, PhD, FRCP, FRCPsych, FMedSci, Anne E. Farmer, MB, ChB, DPM, MRCPsych, MD, FRC, MRC Social, Genetic and Developmental Psychiatry Centre, Institute of Psychiatry, King's College London, UK

Correspondence: Georgina Hosang, MRC Social, Genetic and Developmental Psychiatry Centre, Institute of Psychiatry, King's College London, De Crespigny Park, London SE5 8AF, UK. Email: georgina.hosang@kcl.ac.uk

First received 24 Feb 2012, final revision 12 Sep 2012, accepted 17 Sep 2012

\section{Funding}

G.M.H. is supported by a Medical Research Council (MRC) and Economic Social Research Council (ESRC) UK interdisciplinary postdoctoral fellowship (PTA-037-27-0165). The Depression Case Control study was supported by a MRC grant and the Bipolar affective disorder Case Control study data collection was funded by an unrestricted grant from GlaxoSmithKline Research and Development.

\section{Acknowledgements}

We would like to thank Audrey Morgan, Cerisse Gunasinghe, Katharine Mead, Joanna Gray, Ylva Dahlin, Amanda Elkin, Joanna O'Leary, Nathan O'Neill, Nicola Reynolds, Zainab Samaan, Abraham Stern, Linda Southwick, Kopal Tandon, Alison Wheatley, Richard Williamson, Julia Woods, Sarah Ball, Ophelia Beer, Julian Childs, sam Keating, Rachel Marsh, Penny Machin and Lucy Maddox who were involved with the data collection and management of the studies.

\section{References}

1 Hosang GM, Korszun A, Jones L, Jones I, Gray JM, Gunasinghe CM, et al. Adverse life event reporting and worst illness episodes in unipolar and bipolar affective disorders: measuring environmental risk for genetic research. Psychol Med 2010; 40: 1829-37.

2 Hosang GM, Uher R, Maughan B, McGuffin P, Farmer A. The role of loss and danger events in symptom exacerbation in bipolar disorder. J Psychiatr Res 2012; Aug 3: doi 10.1016/j.jpsychires.2012.07.009 (Epub ahead of print).

3 Johnson SL. Life events in bipolar disorder: towards more specific models. Clin Psychol Rev 2005; 25: 1008-27.

4 Harris T. Recent developments in understanding the psychosocial aspects of depression. Br Med Bull 2001; 57: 17-32.

5 Kendler KS, Karkowski LM, Prescott CA. Stressful life events and majo depression: risk period, long-term contextual threat, and diagnostic specificity. J Nerv Ment Dis 1998; 186: 661-9.

6 Tennant C. Work-related stress and depressive disorders. J Psychosom Res 2001; 51: 697-704.

7 Dunner DL, Patrick V, Fieve RR. Life events at the onset of bipolar affective illness. Am J Psychiatry 1979; 136: 508-11.

8 Bidzińska EJ. Stress factors in affective diseases. Br J Psychiatry 1984; 144 161-6.

9 Honkalampi K, Hintikka J, Haatainen K, Koivumaa-Honkanen H, Tanskanen A, Viinamaki H. Adverse childhood experiences, stressful life events or demographic factors: which are important in women's depression? A 2-year follow-up population study. Aust N Z J Psychiatry 2005; 39: 627-32.

10 Farmer $A E$, McGuffin $P$. Humiliation, loss and other types of life events and difficulties: a comparison of depressed subjects, healthy controls and their siblings. Psychol Med 2003; 33: 1169-75.

11 Hall KS, Dunner DL, Zeller G, Fieve RR. Bipolar illness: a prospective study of life events. Compr Psychiatry 1977; 18: 497-502.

12 Kessing LV, Agerbo E, Mortensen PB. Major stressful life events and other risk factors for first admission with mania. Bipolar Disord 2004; 6: 122-9.

13 Hunt $\mathrm{N}$, Bruce-Jones $\mathrm{W}$, Silverstone T. Life events and relapse in bipolar affective disorder. J Affect Disord 1992; 25: 13-20.

14 Hammen C. Stress and depression. Annu Rev Clin Psychol 2005; 1: 293-319.

15 Johnson SL, Cuellar AK, Ruggero C, Winett-Perlman C, Goodnick P, White R, et al. Life events as predictors of mania and depression in bipolar I disorder. J Abnorm Psychol 2008; 117: 268-77.

16 Beyer JL, Kuchibhatla M, Cassidy F, Krishnan KR. Stressful life events in older bipolar patients. Int J Geriatr Psychiatry 2008; 23: 1271-75. 
17 Ambelas A. Psychologically stressful events in the precipitation of manic episodes. Br J Psychiatry 1979; 135: 15-21.

18 Horesh $\mathrm{N}$, lancu I. A comparison of life events in patients with unipolar disorder or bipolar disorder and controls. Compr Psychiatry 2010; 51: 157-64.

19 Malkoff-Schwartz S, Frank E, Anderson BP, Hlastala SA, Luther JF, Sherrill JT, et al. Social rhythm disruption and stressful life events in the onset of bipolar and unipolar episodes. Psychol Med 2000; 30: 1005-16.

20 Malkoff-Schwartz S, Frank E, Anderson B, Sherrill JT, Siegel L, Patterson D, et al. Stressful life events and social rhythm disruption in the onset of manic and depressive bipolar episodes: a preliminary investigation. Arch Gen Psychiatry 1998; 55: 702-7.

21 Cohen-Woods S, Gaysina D, Craddock N, Farmer A, Gray J, Gunasinghe C et al. Depression Case Control (DeCC) Study fails to support involvement of the muscarinic acetylcholine receptor M2 (CHRM2) gene in recurrent major depressive disorder. Hum Mol Genet 2009; 18: 1504-9.

22 Schosser A, Schloegelhofer M, Fuchs K, Stojanovic M, Mossaheb N, Kindler J, et al. Bipolar disorder susceptibility region on chromosome $3 q 29$ not confirmed in a case-control association study. World J Biol Psychiatry 2011; 12: 309-15.

23 American Psychiatric Association. Diagnostic and Statistical Manual for Mental Disorders (4th edn) (DSM-IV). APA, 1994.

24 Holma KM, Melartin TK, Holma IA, Isometsa ET. Predictors for switch from unipolar major depressive disorder to bipolar disorder type I or II: a 5-year prospective study. J Clin Psychiatry 2008; 69: 1267-75.

25 Chen YR, Swann AC, Johnson BA. Stability of diagnosis in bipolar disorder. J Nerv Ment Dis 1998; 186: 17-23.

26 Jarbin $\mathrm{H}$, von Knorring AL. Diagnostic stability in adolescent onset psychotic disorders. Eur Child Adolesc Psychiatry 2003; 12: 15-22.

27 Sham PC, Sterne A, Purcell S, Cherny S, Webster M, Rijsdijk F, et al. GENESiS: creating a composite index of the vulnerability to anxiety and depression in a community-based sample of siblings. Twin Res 2000; 3: 316-22.

28 Wing JK, Babor T, Brugha T, Burke J, Cooper JE, Giel R, et al. SCAN: Schedules for Clinical Assessment in Neuropsychiatry. Arch Gen Psychiatry 1990; 47: 589-93.

29 McGuffin P, Katz R, Aldrich J. Past and present state examination: the assessment of 'lifetime ever' psychopathology. Psychol Med 1986; 16 : 461-65.

30 Beck AT, Steer RA, Brown GK. Manual for the Beck Depression Inventory-II. The Psychological Corporation, 1996.
31 Brugha T, Bebbington P, Tennant C, Hurry J. The List of Threatening Experiences: a subset of 12 life event categories with considerable long-term contextual threat. Psychol Med 1985; 15: 189-94.

32 Kim JM, Stewart R, Kim SW, Yang SJ, Shin IS, Kim YH, et al. Interactions between life stressors and susceptibility genes (5-HTTLPR and BDNF) on depression in Korean elders. Biol Psychiatry 2007; 62: 423-8.

33 Maciejewski PK, Prigerson HG, Mazure CM. Sex differences in event-related risk for major depression. Psychol Med 2001; 31: 593-604.

34 Miklowitz DJ, Johnson SL The psychopathology and treatment of bipolar disorder. Annu Rev Clin Psychol 2006; 2: 199-235.

35 McGuffin P. Affective disorders. In Essential Psychiatry (eds RM Murray, KS Kendler, P McGuffin, S Wessely, D Castle): 250-83. Cambridge University Press, 2008.

36 Hammen C. Stress generation in depression: reflections on origins, research, and future directions. J Clin Psychol 2006; 62: 1065-82.

37 Bender RE, Alloy LB, Sylvia LG, Urosevic S, Abramson LY. Generation of life events in bipolar spectrum disorders: a re-examination and extension of the stress generation theory. J Clin Psychol 2010; 66: 907-26.

38 Brown GW, Harris TO. The Bedford College Life Events and Difficulties Schedule: Directory of Contextual Threat Ratings of Events. Bedford College, University of London, 1978.

39 Malkoff-Schwartz S, Frank E, Anderson BP, Hlastala SA, Luther JF, Sherrill JT, et al. Social rhythm disruption and stressful life events in the onset of bipolar and unipolar episodes. Psychol Med 2000; 30: 1005-16.

40 Malkoff-Schwartz S, Frank E, Anderson B, Sherrill JT, Siegel L, Patterson D, et al. Stressful life events and social rhythm disruption in the onset of manic and depressive bipolar episodes: a preliminary investigation. Arch Gen Psychiatry 1998; 55: 702-7.

$41 \mathrm{McPherson} \mathrm{H}$, Herbison $\mathrm{P}$, Romans $\mathrm{S}$. Life events and relapse in established bipolar affective disorder. Br J Psychiatry 1993; 163: 381-5.

42 Ambelas A. Life events and mania. A special relationship? Br J Psychiatry 1987; 150: 235-40.

43 Hosang GM, Uher R, Keers R, Cohen-Woods S, Craig I, Korszun A, et al. Stressful life events and the brain-derived neurotrophic factor gene in bipolar disorder. J Affect Disord 2010; 125: 345-49.

44 Mandelli L, Serretti A, Marino E, Pirovano A, Calati R, Colombo C. Interaction between serotonin transporter gene, catechol-o-methyltransferase gene and stressful life events in mood disorders. Int I Neuropsychopharmacol 2007; 10: $437-47$.

Envy spoils. We desire something good in another and must destroy it, unlike the greedy and the jealous who seek to possess it. Envy is in the vandal who defaces the only thing of beauty in a wasteland; in the patient who would rather suffer than admit his neediness by accepting help. We all experience envy, but excessive envy denies what is good, closes down opportunity and deadens us. Conversely, a preponderance of gratitude embraces life with both its challenges and joys, and relishes the good in others. Envy spoils what we secretly desire, and in so doing spoils ourselves. 